\title{
Tsunamis in the East Sea and damages to the coastline of Vietnam
}

\author{
Izmail Kantarzhi and Hoa Nguyen Hai* \\ Moscow State University of Civil Engineering, Yaroslavskoe shosse, 26, Moscow, 129337, Russia
}

\begin{abstract}
According to field surveys as well as data recorded in text documents, it can be said that Vietnam has historically been hit by a tsunami. However, we still do not have enough information to accurately determine the destructive power of these tsunamis against the coastal line of Vietnam. On the other hand, in the South China Sea, there are four potential earthquakes that could lead to tsunamis affecting coastal line of Vietnam. Using models, tsunami simulations as well as computing algorithms, experts say that tsunamis will appear and attack coastal line of Vietnam when there are submarine earthquakes with magnitude of larger than 7 at the fault along Central Asia shelf with an earthquake with magnitude of greater than 8 at the Manila Trench. If an earthquake of magnitude 8 occurs in the south of Hainan, the tsunami impacting coastal line of Vietnam will be greater than $2 \mathrm{~m}$. If an earthquake of magnitude 8 occurs in Manila, the tsunami from Da Nang city to Quang Ngai will reach $4 \mathrm{~m}$. From there we can see that the risk of tsunami occurring and attacking the coastal cities of Vietnam is there, although the probability is not high.
\end{abstract}

\section{Introduction}

Tsunami is a series of waves created when a large volume of ocean water is shifted lightning on a large scale. Earthquakes and large geological shifts above or below the surface, volcanic eruptions and meteorite impacts are likely to cause tsunamis. The effects of the tsunami can be immense, killing by submerging hundreds of thousands of people in hours. We can record the following tsunami disaster:

The 2004 Indian Ocean tsunami was one of the most devastating tsunamis, killing 230.000 people and displacing nearly 1.7 million people. India, Thailand, Somalia, Malaysia and Indonesia are the country's most severely damaged in this natural disaster. In just 40 minutes after the earthquake, a tsunami struck Portugal's capital, Lisbon. Next, the tsunami reached $3 \mathrm{~m}$ high on the English coast while Ireland, North Africa and Barbados were also hit by large waves. The total number of people killed in the earthquake, tsunami that year was estimated at 100 thousand.

In 1883, the eruption of the Krakatoa volcano caused a devastating tsunami, which killed about 40.000 people.

\footnotetext{
* Corresponding author: Nguyenhaihoa@vimaru.edu.vn
} 
In September 1498, a magnitude 8.6 earthquake struck off the coast of Nankaido, Japan, causing a tsunami wave that killed between 26.000 and 31.000 people. On October 28, 1707 , over 5,000 people were killed and about 29.000 houses were destroyed during the Hoei earthquake-tsunami disaster. On June 15, 1896, over 20.000 people in Japan and about 9.000 homes were destroyed during the Sanriku earthquake-tsunami disaster. On March 11, 2011, a magnitude 9 earthquake triggered a tsunami near the coast of Japan, killing nearly 16.000 people, injuring 6.000 people and missing more than 2.000. In addition, 220.000 people have been evacuated, and nearly 750.000 houses have been destroyed. Total damage estimated at 235 billion USD. The Great Yaeyama tsunami in Japan in 1771 killed about 13.500 people and left more than 2.000 homes destroyed. On January 18, 1586, Japan's Ise Bay was hit by a tsunami that left thousands of dead. In 1783, a tsunami struck in Scillia in Italy, killing nearly 1.500 people. On December 28, 1908, the Messina earthquake destroyed many major cities in Italy and left about 75.000 to 200.000 people dead. Only about 10 minutes after the earthquake, three consecutive tsunamis hit the coast of Italy, killing the lives of 2.000 people.

What can we do to reduce the risk of a tsunami for a country? Sophisticated warning systems in the world can detect tsunami by touch sensors. The countries then use the news on television and radio, as well as loudspeakers to alert the public. Japan thrives on public information campaigns to ensure the highest number of citizens are able to behave through school, television, radio and leaflets. Hawaii also has the fastest signposted signal system to secure higher ground in an emergency. Areas like Hawaii have early warning systems and emergency plans. In Japan, the government tested the upright structure, the pedestal platform, and lifted up from the tsunami.

Sensitive buildings such as nuclear power plants will be built offshore and designed to be shut down and moved to "safe locations" as soon as the earthquake is detected. Instead of blocking waves, we allow waves to pass through the structure and produce the least damage. The big door and window is where the water goes through. The goal of the design is to protect the building and make it easier to repair later, assuming that the person has run all the way up. Inside doors are aligned rather than intertwined. If the door is confused, the waves are stocked inside the house. The only way to eliminate the risk associated with the tsunami is not to live near the coast. That reminder has been made before. After the tsunami that devastated Hawaii's Hilo city in 1946 and 1960, the government moved its inhabitants deep into the land. The task of the paper is to present the results of the analysis of the author as well as other experts currently working in Vietnam on the risk of occurrence of tsunami waves affecting the area coastal line of Vietnam. Therefore, we need to proactively analyse and analyse these risks so as to take measures to prevent and minimize damage to coastal line areas of Vietnam

\section{Tsunami risks for Vietnam}

Previously in Vietnam, due to difficult economic conditions, along the coast there were only some tide stations to record hydrographic data. As a result, insufficiently sparse data and credibility are needed to analyse the tsunami. For that reason, in many cases, tsunami information is only provided through surveys in coastal communities and explored in a variety of historical literature. In the first attention phenomenon, there was an unusually high wave of attack on the coast of Tra Co (Figure 1) in 1978. There was a high wave from $2 \mathrm{~m}$ to $3 \mathrm{~m}$ impacting the coast several times, damaging the walls and trees near the coast [11]. Also, in March 2008, some experts went to the field survey and found that the waves only caused flooding in a narrow area, with only a $10 \mathrm{~m}$ gap. On the other hand, most of the incoming waves are dissipated quickly. Such data is not sufficient to conclude that the waves mentioned above are tsunamis. It is possible that the waves are turbulent that have 
been associated with rising tides. The second phenomenon is recorded that the tsunami was attacked on the coastal line of Vietnam in the last year of the 19 th century and the beginning of the 20 th century. At that time there appeared waves of over $3 \mathrm{~m}$, attacked Dien Chau coast, North Central Vietnam (Figure 3). As a result, more than one kilometre of inundation was caused by the coast, and flooding was more than $1.5 \mathrm{~m}$. Waves destroyed many homes, but no information on the number of deaths [11].

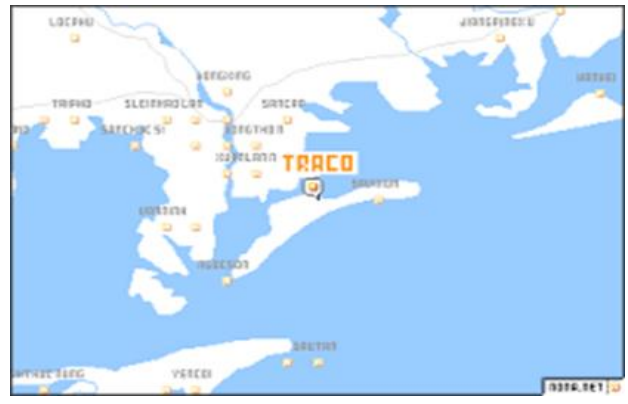

Fig. 1. Tra Co town.

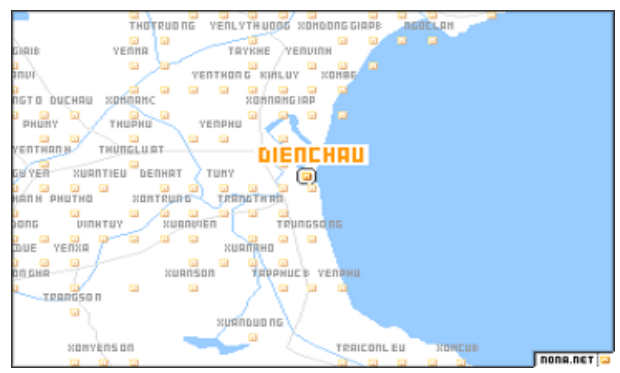

Fig. 3. Dien Chau city.

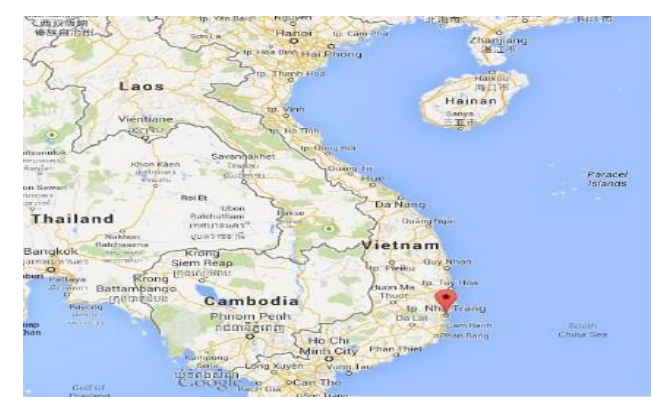

Fig. 2. Nha Trang city.

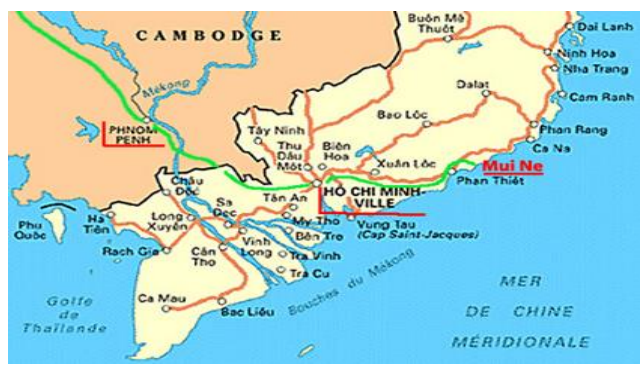

Fig. 4. Mui Ne town.

The third tsunami was recorded by Dr. Armand Krempt. Accordingly, in 1923 high waves hit the coastal city of Nha Trang (Figure 2). Dr. Yersin's horse nursery is located at a distance of about 5-6 m from the coast. This event involved the eruption of the volcanic Asylees, causing an earthquake of magnitude 6.1. On the other hand, experts conducted a survey at the coast of Binh Thuan Province (including Mui Ne in Figure 4) by interviewing local people. Many responded that in 1923, shortly after the Volcanic Ashes erupted, a strong tsunami struck Mui Ne (Figure 4).

The fourth tsunami event may be recorded in a Vietnamese history book titled "Dai Nam Trung Luan Chinh Bien" that "In September 1877, there was an earthquake in Binh Thuan experts estimate that the magnitude 7 earthquake [11]. The fifth tsunami event may also be recorded in a Vietnamese history book titled "Hien chuong Loai chi" in 1882, there was an earthquake, after high waves, with many explosions. within a day. In April 2006, a group of experts went to investigate tsunami traces along the coastal line of Vietnam. The team surveyed 6 areas: Cua Lo, Song Cau, Nha Trang, Phan Rang, Phan Thiet and sampled at different sediment layers for analysis. They discovered a tsunami with a maximum height of $18 \mathrm{~m}$ attacking a $1,000 \mathrm{~km}$ coastline in central Vietnam [11].

With all the above-mentioned survey results, it is possible to say that there are likely to be tsunami events on coastal line of Vietnam. However, the data is not reliable enough to confirm this, so we need further analysis. 

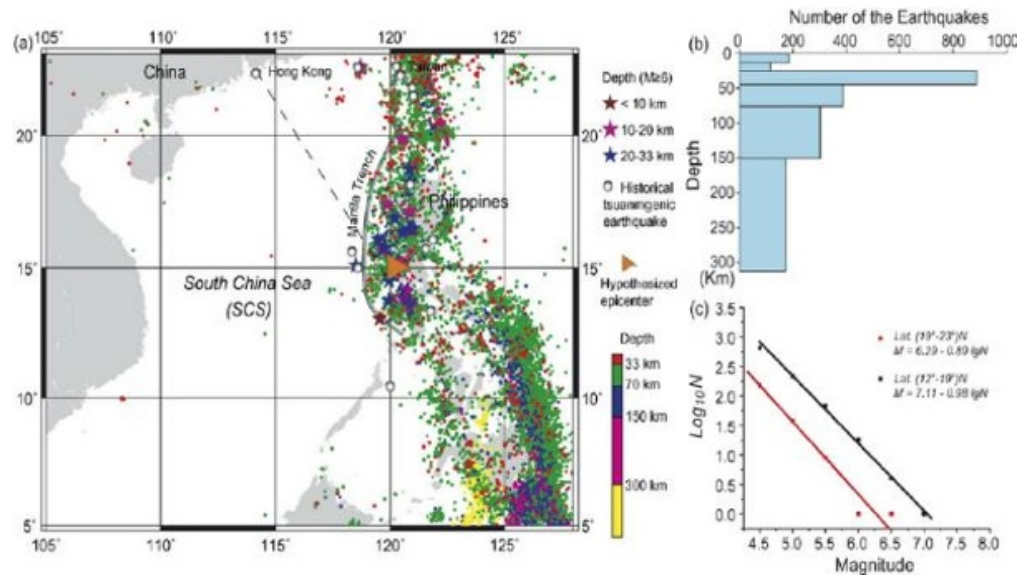

Fig. 5. Faults and seimic activities in the West South China Sea

\section{Designing standard for the zone of tsunami risk}

The compulsory, irrespective of the proportioning results, constructional measures to secure tsunami resistance of offshore and onshore facilities, include the following: creation of tsunami resistant constructions, whose sizes, shapes, structures, and materials are minimally subject and maximally resistant to hydrodynamic impact (framed structures, streamlined forms, water-repellent materials, flexible and damping devices, etc). The design of structures for tsunami resistance is compulsory for the important constructions and at the same time the design standards of maritime hydrotechnical structures must be used. The design of structures for the tsunami impact must be carried out on the basis of loads depending on the design of height of runup $H_{100}$, taken for the zone being considered for: all structures, besides temporary ones, for the design tsunami. Hydrotechnical engineering structures of increased extent of responsibility for the maximum design tsunami. General maps (1:1000000-1:100000), detailed maps (1:100000-1:25000), and local/object maps of tsunami microzoning $(>1: 25000)$ are used in depend of importance of design targets. Tsunami microzoning maps must be carried out by application of physical and mathematical simulation. Serviceability of the structure is determined by the limit state occurrence which is assigned in advance depending off operation condition: operation is impossible, hindered/limited, or inexpedient [5]. For the structures, located on the Tsunamihazardous area, combined action of tsunami and earthquake is not considered. For the structures, located on the Tsunami-hazardous area, when considering the tsunami impact, one must take into account permanent deformations of foundations and structural elements stipulated by earthquake impact.

During the relevant justification of the most important structures on the territories one can consider the simultaneous impact of aftershock inertial earthquake load and the tsunami impact. When designing maritime hydrotechnical structures for the tsunami impact one must take into consideration the situation stipulated by the decrease in the design sea level, as well as by subsoil erosion and outflow processes.

The parameters of the design event under consideration are determined for each particular construction type taking into account local conditions. The values of the parameters specified (value of the decrease in the design level, filtration rate etc) are determined by the methods of physical and (or) mathematical simulation. The buildings, located in tsunamihazardous zones, should be designed taking into account hydrodynamic impacts on the loadbearing structures and foundations. If it is impossible to provide structural strength and 
sustainability of the building under the impact of tsunami, its operation is not permitted [5]. It is recommended to make lower floors the buildings, located in the flooding zone, open, living accommodations should be located above the ground floor. The life support system elements (emergency generators, electrical distribution units and motors of lifts) must be located on the floors not exposed to the flood hazard.

Secondary impacts stipulated by the movement of massive objects (fuel tanks, motor transport, industrial equipment, structure elements, ice, etc.) should be minimized, if possible. The marks of the bottom of bridge superstructures must be higher than the height of runup value with design margin. The bridge footings (both bridge abutments and middle supports) must withstand the tsunami impact.

To protect the territories with the relevant technical and economic feasibility the special structures can be erected (near-shore dams, breakwaters, river dikes) [5]. It is recommended to plant strips of forest and shrubs on tsunami-hazardous shores. In the zones, exposed to the flood, in the near shore zone one must provide for the construction of framed platforms with bearing parts in the form of space frameworks to secure vertical evacuation. In flood zones, for the territories, being explored new, it is not recommended to construct residential buildings.

The transport systems should be designed taking into account the possibility of fast mass evacuation from flood zones.

For the earlier explored territories, it is recommended to correct general layouts with gradual demolition of residential buildings in flood zones [5]. As an example of the standard application we considered tsunami resistance of the port hydrotechnical structures on the Sakhalin island.

The tsunami impact was determined in respect of the following projects:

quay made of floating caissons (the Korsakovport)

quay made of caisson masonry (the Korsakovport)

supports of the bridge-type quay (the Kholmskport).

The basic data for the design of the tsunami impact on the quays made of floating caisson and caisson mason work in the Korsakov port are the following:

Water depth $d=8 \mathrm{~m}$

Height of runup $H_{100}=1.4 \mathrm{~m}$

Wave period $\mathrm{T}=8 \mathrm{~min}$.

According to the methodology, given in the standard, the total wave-impact load on the vertical wall is equal to

$P=195.7 \mathrm{kN}$. The load $P$ is applied at the distance of $4.8 \mathrm{~m}$ from the bottom.

The basic date for the design of the load on the the bridge-type quay supports in the Kholmsk port are taken as follows:

Water depth at the support $d=8.5 \mathrm{~m}$,

Wave height $H_{100}=3.2 \mathrm{~m}$

Support diameter $D=4 \mathrm{~m}$.

The total wave-impact load on one support $4 \mathrm{~m}$ wide will amount to $309 \mathrm{kN}$.

After the loads had been determined, the structure stability against sliding was checked and each of the three projects-representatives under consideration was overturned. In connection with considerable dimensions of the structure the plane stress problem was considered, and the analysis of forces was carried out by $1 \mathrm{~m}$ of the structure for the retaining walls in the Korsakov port and the buttress $4 \mathrm{~m}$ wide of the berth bridge conduit in the Kholmsk port. At the same time, for the space structures both the tsunami wave setup with the height $h$ and the decrease in the water level before the wave arrival taken equal to $h$ and $2 h$ were considered. The calculations showed that, with practically equal loads, the berth in the port Korsakov has lower values of the stability margin factor than the berth [5]. 
The load-bearing capacity of the structure and its elements will be provided subject to the following condition.

$$
\gamma_{l c} F \leq R /\left(\gamma_{n}\right)
$$

where $\gamma_{l}-$ combination factor, is equal to:

1.0 for basic load combination

0.95 with super load including earthquake load at the level of the strength-level

earthquake, with the yearly probability of 0.01 and less

0.85 - with earthquake load of the maximum strength-level earthquake level

$F$ - general value of the force impact (strength, moment, stress)

$R$ - general value of the load-bearing capacity

$\gamma_{n j}-$ safety factor, equal to 1.15 for the structure

The berthing structures made of floating caissons and caisson mason work have sufficient load-bearing capacity against sliding and overturning both during the tsunami waves setup and during the decrease in the water level down to two wave heights [5].

\section{Numerical modeling of tsunami risks in Vietnam}

The Nami Dance program for calculating tsunami waves was developed jointly with Professor Yalciner (Turkey) and Professor Imamura (Japan). This package performed well in numerous benchmark tests and recommended by UNESCO for tsunami modelling. Head of the Laboratory of VGIO A.L Zaitsev in 2005-2006 was an instructor in special courses on tsunami modelling organized by the International Tsunami and UNESCO Centre in Malaysia (Kuala Lumpur) and Belgium (Oostende). Nami Dance was repeatedly used to model the historical events of the tsunami. It also makes it possible to calculate the effect of a tsunami wave on structures, which makes it possible to take into account not only the wave height, but also its power characteristics, when assessing the tsunami of the risk.

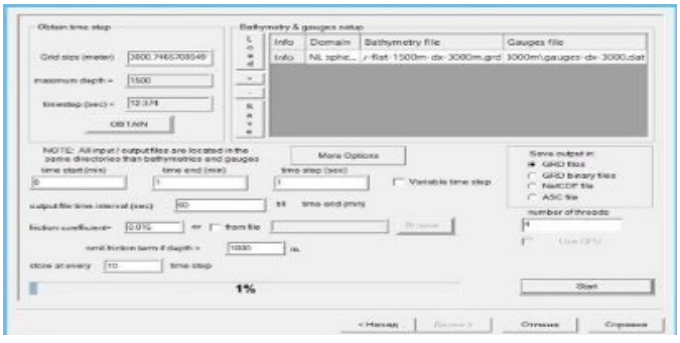

Fig. 6. Interface program NAMI-DANCE [12]

Let's illustrate the work of some blocks of the program. Consider, for example, a new block named in the menu "Source". Here you can choose the "Seismic Fault", which is specified by the parameters: "the angle between the meridian and the axis of the fault, "Fracture depth", "fault length", slope angles and fault coordinates or "Test Fault", which is an ellipsoid specified by parameters such as "amplitude at the centre", " length along the $\mathrm{x}$ axis, m "," length along the y axis, m ", coordinates of the focus [12]. To calculate the tsunami wave, this version of the program uses improved code written in the $\mathrm{C}++$ programming language (this is a more advanced language than the Fortran language on which the original TUNAMI program was written). To calculate, you need to enter the menu "Count the tsunami" - "calculation" and select "Start" - "run". In the first window "Pane 11", you can specify a file with a tsunami focus (seismic or hypothetical) and set the 
event time (in model calculations, the event time is identified with zero). If there were several jerks, then files with them are set and the time of the start of each jog is set (it is possible to set up to 4 jerks). Then, after pressing the "Next" button - "next", go to the next menu "Panel 2", in which files with bathymetry, dots and grid points are set. Here, the start times of the "time start (min)" account, the end of the account "Time end (min)", the step between the "time step (sec)" iterations, the step for calculating the "runup step (sec)" and the frequency with which output files will be created. The software complex NAMIDANCE allows you to prepare data for presentation, that is, to build three-dimensional drawings using the DirectX graphics library. You can also build a video file in avi format. To do this, go to the option "3D plot", then open the "Setting" window. In this option, to run the program, you need to enter a file with bathymetry data, a wave data file, inscriptions (if required), coordinates of the inscription position (if required). In order to create files for conversion to a video file (avi), you need to put a flag at the bottom of the window near the "Avi Preparing" and then set the animation parameters: the start time, the end of the action and the step with which the files will be taken. The software package is designed in such a way as to make it as easy as possible for the user to work. For example, to create an animation after the parameters are entered, the program will do its own work. Threedimensional drawings will appear in the working area of the window, which satisfy the given conditions [12]. Thus, the computer complex NAMI-DANCE (NAMI-DANCE) allows not only to reduce the counting time, but also significantly simplifies the process of processing the resulting information about the simulated tsunami. It received a certificate of State registration of computer programs No. 2014611028 of January 22, 2014. This complex was recommended by UNESCO for tsunami calculations in 2005, and the author of the thesis worked as an instructor in a series of courses organized under the auspices of the International Oceanographic Committee of UNESCO. It is adopted by specialists from a number of countries: Turkey, Russia, India, Sri Lanka, Malaysia, NAMI-DANCE Computing Complex is implemented in the system of tsunami alerts in Turkey and Malaysia. We also note that we have developed programs for the automatic retrieval in real time of earthquake data of geophysical services and sea surface oscillations from the DART buoy system, which are necessary for the rapidity of tsunami calculations after the earthquake that has just happened, which we do not do well on. The numerical calculation package for long waves described in this section within the framework of the nonlinear theory of shallow water has been used further to carry out most numerical calculations.

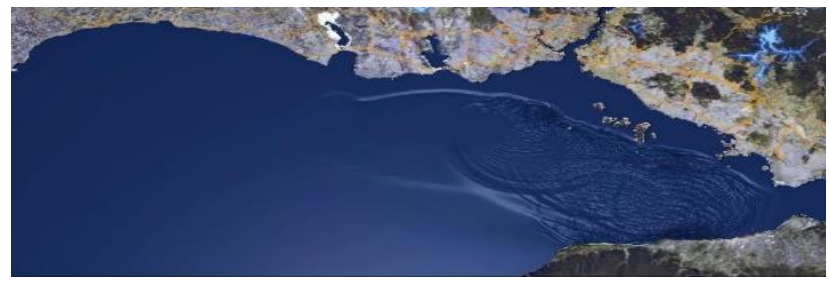

Fig. 7. Three-dimensional wave image obtained after program execution [12]

\section{Conclusions}

Based on the results of the studies, the following conclusions:

- The specific features of loads on structures from tsunami waves in the coastal zone of Vietnam are considered. Characteristics of the tsunami hazard zone for Vietnam. 
- From the above analyses, it can be seen that there is always a possibility of tsunami attacking the coastal line of Vietnam, however this possibility is relatively low. Today, with the socio-economic development, many constructions have been built along the coast, so if a tsunami suddenly hit the damage to people and structures is very large. Therefore, we need to consider carefully to prepare for prevention to reduce damage.

- We can use the NAMI-DANCE software to calculate the effect of a tsunami wave on structure that on the coastal line of Vietnam.

\section{References}

1. D.T. Cao, E.A. Rogozhin, T.L. Ngo, H.T. Nguyen, X.B. Mai, V.D. Le, T.T. Nguyen, Preliminary results of paleo-tsunami research in Vietnam (2007)

2. B.C. Bautista, M.L.P. Bautista, K. Koike, F.T. Wu, R.S. Punongbayan, A new insight on the geometry of subducting slabs in northern Luzon, Philippines (2001)

3. M.L.P. Bautista, B.C. Bautista, J.C. Salcedo, I.C. Narag, Tsunami Catalog of the Philippines (1589 to 2005), 6th ASC Symposium (Bangkok, Thailand, 2006)

4. P.F. Chen, K.F. Ma, L.W. Liao, C.C. Lin, Review of seismic activities in the Malina-Taiwan subduction zone Appraisal of tsunami impacts for offshore eastern Taiwan earthquakes. Workshop on a system approach for tsunami warning and hazard mitigation in the South China Sea Region, Taiwan (2007)

5. I. Nudner, M. Klyachko,V. Maximov, V. Filkov, About Regional Standard "Buildings, Structures, and Safety Requirements Under Tsunami Impact" (2012)

6. S. Kirby, E. Geist, W.H.K. Lee, D. Scholl, R. Blakely, Tsunami Source Characterization for Western Pacific Subduction Zones: A Preliminary Report, in "DART Network Optimization: Workshop Report" (2005)

7. V.L. Nguyen, Q.H. Duong, T.X. Bui, B.D. Nguyen, Characteristics and properties of earthquake in South China Sea and surrounding areas (2007)

8. V.V. Titov, F.I. Gonzalez, Implementation and testing of the method of splitting tsunami, (NOAA Technical memorandum ERdL PMEL-112, 1997)

9. V.T. Ca, T. Tran, K.D. Nguyen, Numerical model for the calculation of flood propagation on very complex topography (2005)

10. V.T. Ca, Tsunami scenarios for Vietnamese coastal water (Report submitted to The Ministry of Natural Resources and Environment in Vietnamese, 2008)

11. V.T. Ca, N.D. Xuyen, Tsunami risk along Vietnamese coast (2008)

12. A.I. Zaytsev, Modeling of nonlinear long waves of tsunami type in the framework of the theory of shallow water and its dispersion generalizations using the computer complex NAMI-DANCE (2018) 